\title{
Researcher urges Health Canada to suspend "unethical" diabetes drug trial
}

Published at www.cmaj.ca on May 26

$\mathrm{R}$ egulators around the world should pull the type 2 diabetes drug rosiglitazone (Avandia ${ }^{\circledR}$ ) from the market and suspend a clinical trial that includes 34 sites in Canada, says Dr. David Juurlink, a Canadian researcher who has studied the drug.

"Every national regulatory agency should re-examine the use of this drug and the status of this trial in their jurisdiction, and they should seriously question whether the trial should continue and whether this drug should remain available," says Juurlink, a research scientist with the Institute of Clinical Evaluative Science, and the head of clinical pharmacology and toxicology at the Sunnybrook Health Sciences Centre in Toronto, Ontario. "That includes Health Canada."

Earlier this month, Juurlink joined forces with Public Citizen, a Washington, DC-based citizens' advocacy group, to write to the United States Food and Drug Administration (FDA). They urged the FDA to stop the Thiazolidinedione Intervention in Vitamin D Evaluation (TIDE) clinical trial that it had ordered manufacturer GlaxoSmithKline to conduct.

"Clinical equipoise requires that no subject receive an intervention known to be inferior to current standards of care," the letter states. "The TIDE trial continues to recruit patients despite a lack of clinical equipoise, exposing thousands of high-risk patients with diabetes to a drug with an unfavorable safety profile and no clinical advantage over its comparator."

In 2007, the FDA issued a safety alert about the possible association between rosiglitazone and an increased risk of heart problems. It has continued to review the drug, and as a result mandated GlaxoSmithKline to compare rosiglitazone and pioglitazone (Actos®), as well as to compare rosiglitazone to

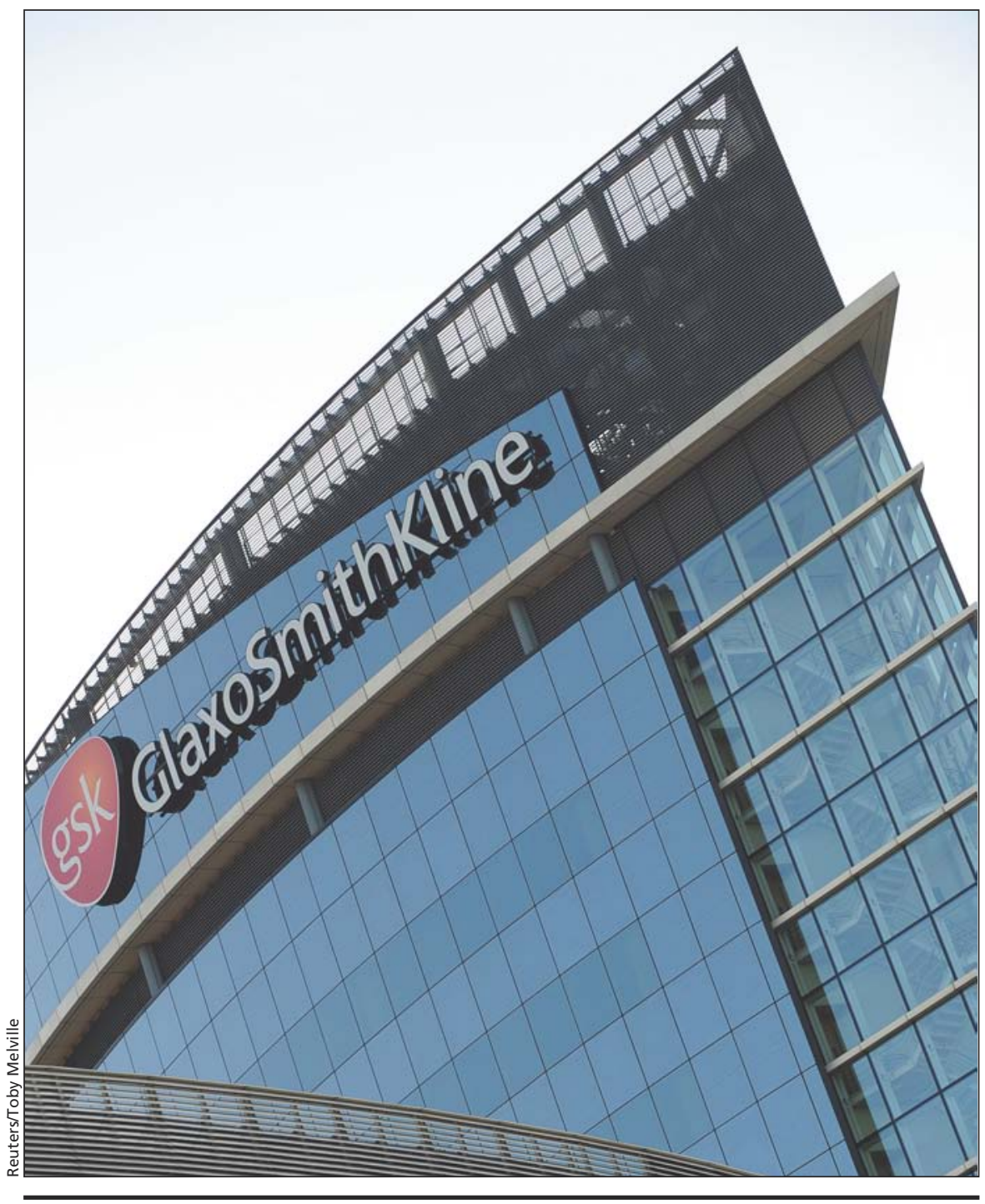

In 2007, the US Food and Drug Administration issued a safety alert about the possible association between the diabetes drug rosiglitazone and increased risk of heart problems, and in 2009 ordered its maker, GlaxoSmithKline, to conduct a clinical trial.

placebo. Health Canada also issued a "Dear Doctor" letter warning physicians not to prescribe rosiglitazone to patients receiving insulin, or in combination with several other medications.

One of the TIDE trial's goals is to test the cardiovascular effects of longterm treatment with both drugs. The study, which is to involve 16000 patients, is recruiting in 14 countries including Canada and is scheduled to finish enrolling patients in 2015.

But since the FDA ordered the study in 2009, new evidence has surfaced about rosiglitazone, says Juurlink. "I think any reasonable person could look at the TIDE trial now and ask whether it is ethically defensible," he says.

But Dr. Hertzel Gerstein, a diabetes researcher at McMaster University in 
Hamilton, Ontario, who is the principal investigator of the international trial, says it is an important study and there is no evidence that either of the two drugs caused harm.

"All of the best evidence to date has not come to any conclusive finding," Gerstein told CMAJ in an interview from Europe, where he was attending a scientific conference. "These drugs may have cardiovascular benefits both of them - or they may have no effect. Or possibly they may harm. We just don't know."

He insisted that "if there was evidence that either or both drugs caused cardiovascular events, obviously we would not be doing this study."

In August 2009, Juurlink published an observational study in the $B M J$ involving nearly 40000 patients taking Avandia ${ }^{\circledR}$ or Actos ${ }^{\circledR}$ between 2002 and 2008. He and his colleagues concluded that there is no reason for physicians to continue to prescribe rosiglitazone, because people wih diabetes treated with it have a higher risk of heart failure and death than those taking pioglitazone. (The study also indicated that pioglitazone is associated with heart problems, although to a lesser degree). The FDA has said it is reviewing the $B M J$ study, as well as other recent evidence.

Rosiglitazone's safety profile has motivated growing concern in the US, where Congress has already held hearings into the drug's safety.

The FDA has announced it will hold its own public hearing in July to present all known heart-related safety data on rosiglitazone, and to provide an updated assessment of the risks and benefits of using the drug.

But Juurlink and Dr. Sidney Wolfe, the director of health research at Public
Citizen, believe the FDA should suspend the trial immediately, on the grounds that it is unethical to knowingly give participants in the rosiglitazone arm a drug that is more harmful than pioglitazone, the medication administered in the other arm of the trial.

Juurlink and Wolfe also question the detail provided on the consent form that some trial participants signed, a form that has surfaced as part of the evidence in lawsuits levied against GlaxoSmithKline in US courts.

Calling the TIDE trial an "unethical experiment," Wolfe told members of Congress that the price of getting definitive proof about what other studies have already suggested "will almost certainly be measured in the lives of study subjects who have been incompletely informed about the available evidence regarding the risks and benefits of participation."

The consent forms describe the study and the side effects of the drugs "and are providing appropriate information for patients," says Gerstein.

Health Canada declined to provide a spokesperson to answer questions about rosiglitazone but said in a written response to $C M A J$ inquiries that it "continues to monitor rosiglitazone-and pioglitazone-containing products and will keep health care professionals and Canadians informed."

Juurlink points to the fact that the American Diabetes Association and the European Association for the Study of Diabetes have both issued statements saying rosiglitazone has no advantage over pioglitazone. They have recommended that physicians not prescribe rosiglitazone.

"There is no reason to use Avandia ${ }^{\circledR}$ in the setting of a clinical trial or in practice," Juurlink agrees.
Neither Health Canada nor the Canadian Diabetes Association have gone that far, however, a fact that "GlaxoSmithKline pointed out in a written response to CMAJ questions about whether the trial should be suspended.

"The Canadian Diabetes Association's 2008 Clinical Practice Guidelines continue to include rosiglitazone as a second-line therapy after metformin," the company said in its statement. "The science shows us that Avandia ${ }^{\circledR}$ is safe and effective when used appropriately and in accordance with labelling. Avandia ${ }^{\circledR}$ is an important treatment option for physicians who often need to increase medicine prescriptions to help their patients maintain their blood sugar levels."

Juurlink called the Canadian Diabetes Association's practice guidelines "bad advice."

Health Canada also believes that "at this time, the benefits of rosiglitazone and pioglitazone are still considered to outweigh the risks when used as directed in the Canadian Product Monographs," it said in a statement. The health regulator would not comment on the TIDE trial specifically, citing proprietary concerns.

Sales of rosiglitazone have fallen in Canada since 2007, when a major study was published in the New England Journal of Medicine raising safety concerns, according to data collected by IMS Health, a private Canadian company that tracks prescription drug sales. In 2007, there were 1117691 prescriptions dispensed for Avandia ${ }^{\circledR}$, for a value of $\$ 250$ million. In 2009, there were 578998 prescriptions dispensed in Canada, with a value of $\$ 158$ million. - Laura Eggertson, Ottawa, Ont.

DOI:10.1503/cmaj.109-3268 